\title{
Design of Thermoresponsive Polymers with Aqueous LCST, UCST, or both: Modification of a Reactive Poly(2-vinyl-4,4-dimethylazlactone) Scaffold
}

Yicheng Zhu, Rhiannon Batchelor,,$^{\dagger}$ Andrew B. Lowe, ${ }^{\dagger,+}$ Peter J. Roth ${ }^{\dagger,+}, *$

${ }^{\dagger}$ Centre for Advanced Macromolecular Design (CAMD), School of Chemical Engineering, University of New South Wales, Sydney, NSW 2052, Australia

$\$$ present address: Nanochemistry Research Institute (NRI) and Department of Chemistry, Curtin University, Bentley, Perth WA 6102, Australia

*corresponding author email: Peter.Roth@curtin.edu.au

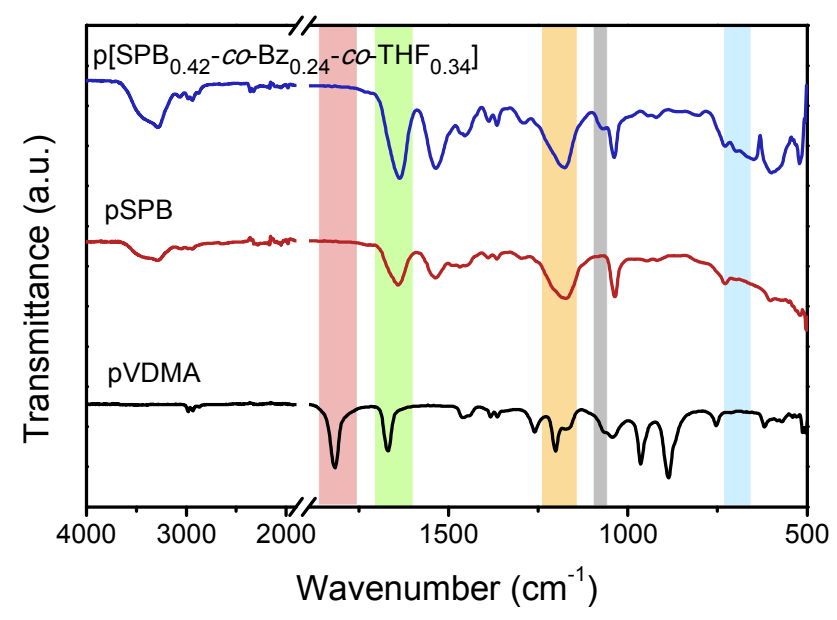

Figure S1. FT-IR spectra of the pVDMA precursor (bottom), homopolymer pSPB (middle), and terpolymer $\mathrm{p}\left[\mathrm{SPB}_{0.42}-\mathrm{co}-\mathrm{Bz}_{0.24}-\mathrm{co}-\mathrm{THF}_{0.34}\right]$ (top). The characteristic bands of azlactone $\mathrm{C}=\mathrm{O}$ stretching (red), the azlactone $\mathrm{C}=\mathrm{N}$ stretching and amide $\mathrm{C}=\mathrm{O}$ stretching regions (overlapping, green), sulfobetaine $\mathrm{S}=\mathrm{O}$ stretching (orange), aliphatic ether $\mathrm{C}-\mathrm{O}$ stretching (gray), and the aromatic benzene $\mathrm{C}-\mathrm{H}$ bending (blue) are marked. 


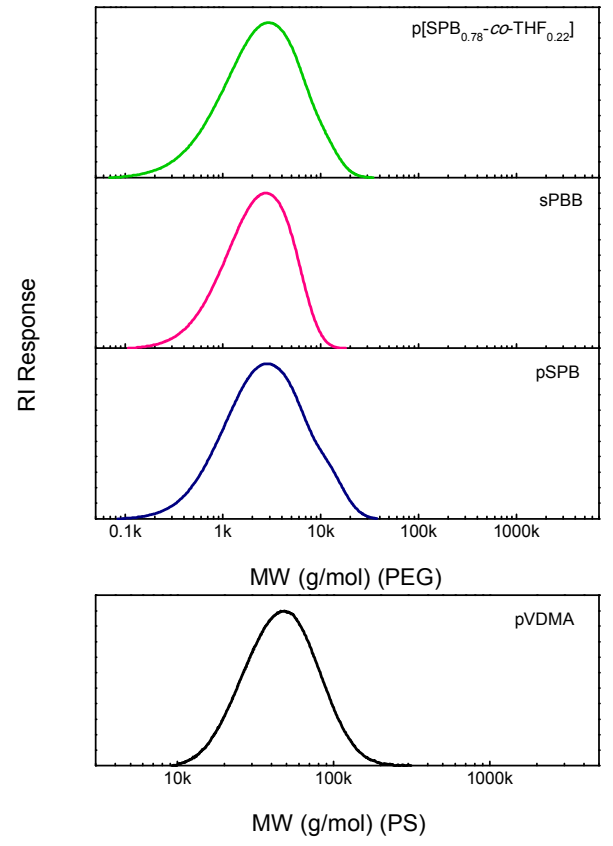

Figure S2. SEC curves of the pVDMA precursor (bottom) measured in dimethylformamide (polystyrene calibration), and of three zwitterionic (co-)polymers measured in aq. $\mathrm{NaCl}$ (poly(ethylene glycol) calibration). Due to the different eluents and column types, a direct comparison is difficult.

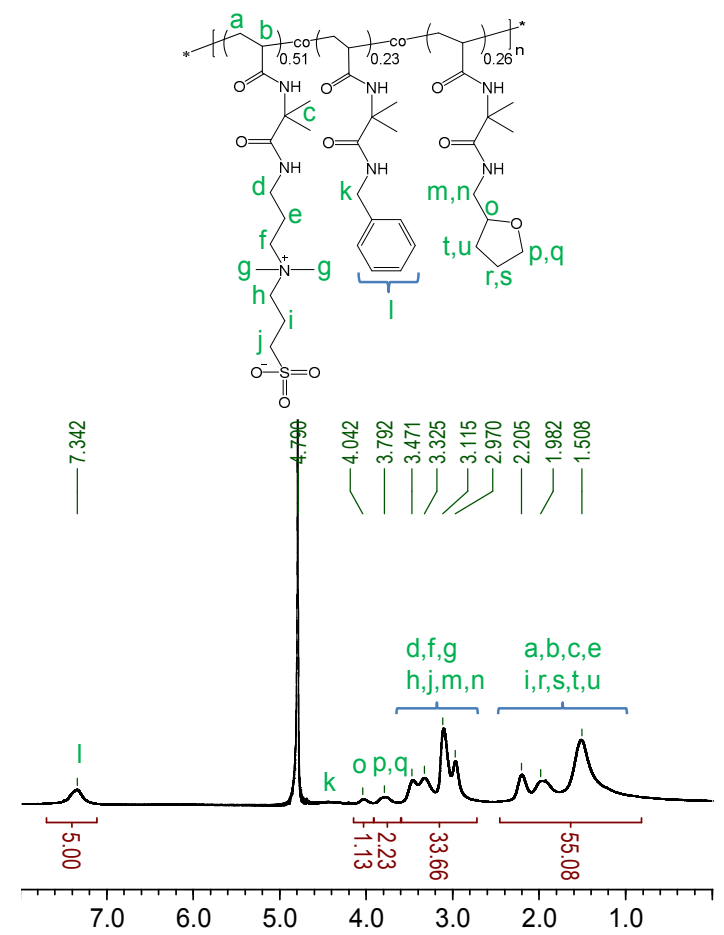

Figure S3. Representative ${ }^{1} \mathrm{H}$ NMR spectrum of $\mathrm{p}\left[\mathrm{SPB}_{0.51}-c o-\mathrm{Bz}_{0.23}-c o-\mathrm{THF}_{0.26}\right]$ with peak assignments and integration. 


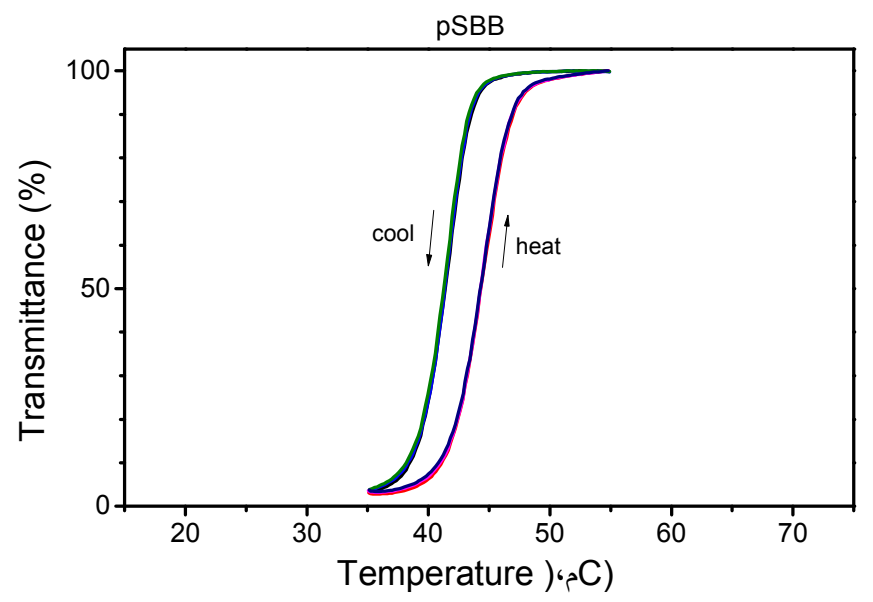

Figure S4. Representative cycling turbidity measurement showing good reproducibility and a hysteresis of $3{ }^{\circ} \mathrm{C}$.

Colours represent three different heating/cooling cycles.
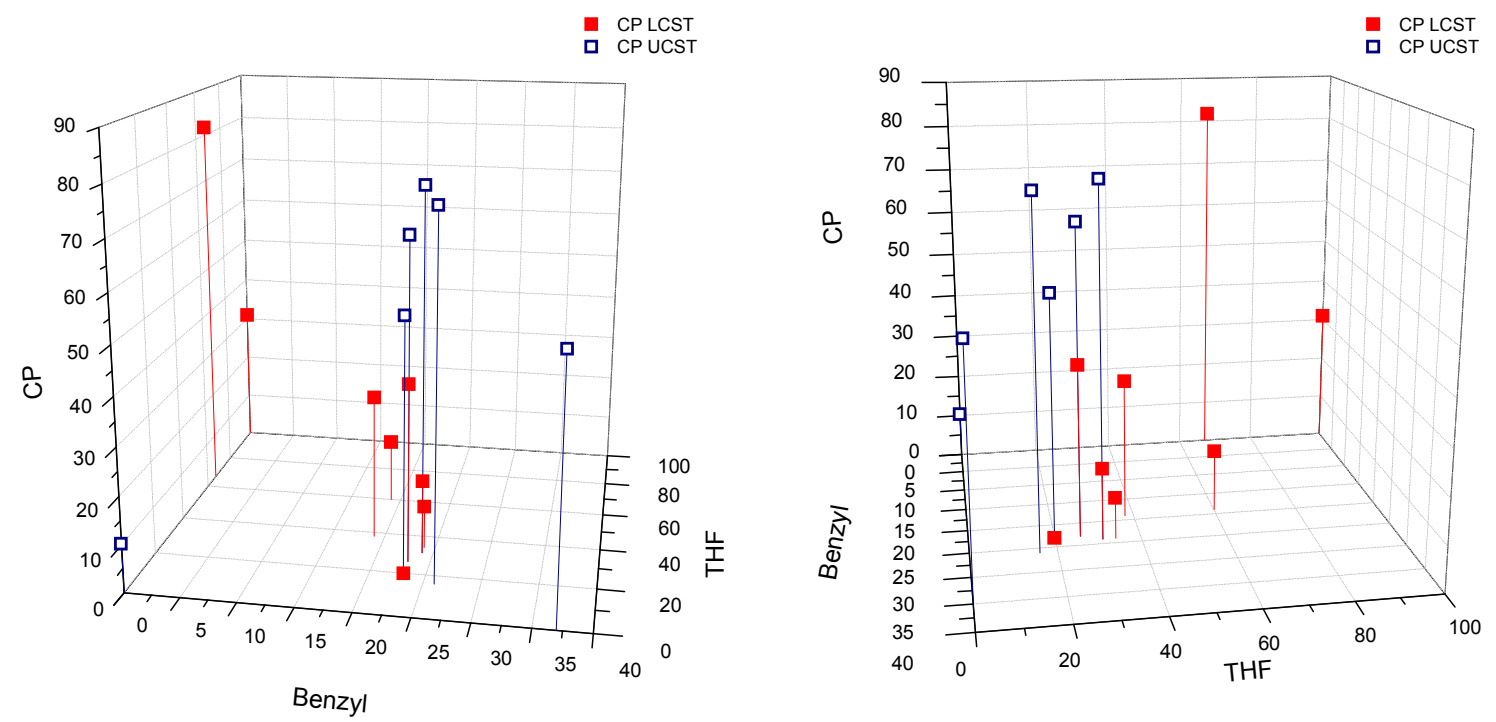

Figure S5. 3D-phase diagram of cloud points ( solid red = LCST, hollow blue = UCST) vs. molar benzyl and THF content (residual percentage $=$ SPB units). The two plots show the same diagram from two different angles. In order to identify species with double LCST and UCST thermoresponsiveness, the region with $0.15-0.25$ molar benzyl content was specifically targeted in this study (see the easier-to-read 2-D phase diagram in Figure 2B). 


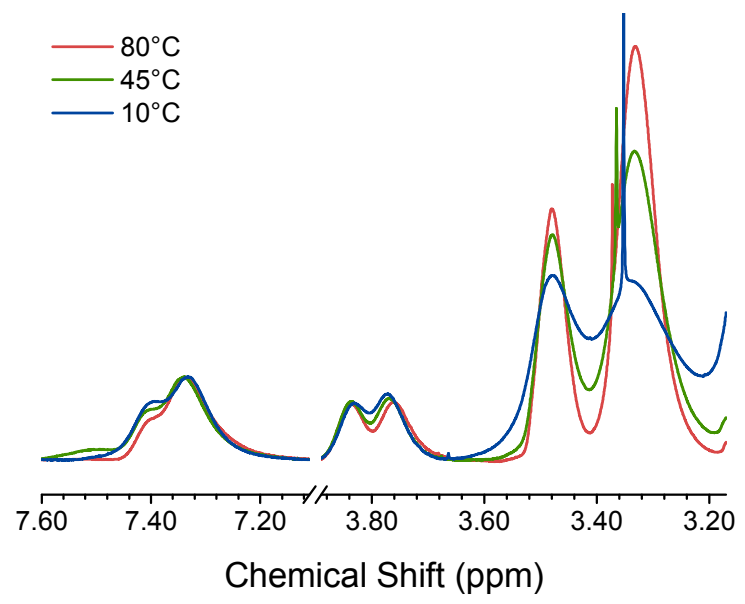

Figure S6. Sections of ${ }^{1} \mathrm{H}$ NMR spectra of $\mathrm{p}\left[\mathrm{SPB}_{0.48}-c o-\mathrm{Bz}_{0.15}-c o-\mathrm{THF}_{0.37}\right]\left(\mathrm{D}_{2} \mathrm{O}, 500 \mathrm{MHz}\right)(\mathrm{Table}$, entry 15) recorded at $10{ }^{\circ} \mathrm{C}$ (blue), $45^{\circ} \mathrm{C}$ (green) and $80{ }^{\circ} \mathrm{C}$ (red) in $\mathrm{D}_{2} \mathrm{O}$. 